\title{
DETERMINING THE CLAY/ORGANIC CARBON RATIO BY VISIBLE NEAR INFRARED SPECTROSCOPY
}

\author{
Maria Knadel $^{1 *}$, Yi Peng ${ }^{1}$, Cecilie Hermansen ${ }^{1}$, Trine Norgaard ${ }^{1}$, René Gislum², \\ Lis Wollesen de Jonge ${ }^{1}$, Per Moldrup ${ }^{3}$, and Mogens H. Greve ${ }^{1}$ \\ ${ }^{1}$ Dept. of Agroecology, Faculty of Science and Technology, Aarhus University, Blichers Allé 20, PO box 50, \\ DK-8830 Tjele, Denmark. \\ 2 Dept. of Agroecology, Faculty of Science and Technology, Aarhus University, Forsøgsvej 1, DK-4200 \\ Slagelse, Denmark. \\ ${ }^{3}$ Dept. of Civil Engineering, Aalborg University, Sofiendalsvej 11, DK-9200 Aalborg SV, Denmark.
}

Corresponding author: Maria.Knadel@agro.au.dk

The recently presented Dexter et al. (2008) threshold (ratio of clay to organic carbon (OC) of $10 \mathrm{~kg} / \mathrm{kg}-1$ ) is a good indicator for soil functional properties. However, the conventional analysis of $\mathrm{OC}$ and clay are costly and time consuming, thus an alternative method to quantify $\mathrm{OC}$, clay or clay/OC ratio directly would be valuable. Visible near infrared spectroscopy (vis-NIRS) is a cost-effective method for soil analysis and was tested here for the prediction of clay/OC ratio. Soil samples from two agricultural fields in Denmark $(\mathrm{N}=115)$ were analyzed. Partial Least Squares regression (full cross-validation) was performed on $80 \%$ randomly selected samples to correlate soil spectra with OC, clay and clay/OC. The robustness of calibration models was tested on the remaining $20 \%$ of the samples. The soil from the two study sites vary greatly presenting clay/OC ratio between 1.20 and 10.43 . Successful calibration results for $\mathrm{OC}$, clay and clay/OC ratio were generated. The OC content was predicted with a RMSEP of $0.23 \%, R^{2}$ of 0.96 , whereas the prediction of clay resulted in $\mathrm{RMSEP}=0.94 \%$, and $\mathrm{R}^{2}=0.94$. The most successful predictive ability reported was of the clay/OC ratio ( $R M S E P=0.42$, and $R^{z}=0.97$ ) with the most important absorption bands related to both clay minerals (1421, 1910 and $2206 \mathrm{~nm}-\mathrm{OH}$ bonds and 429, 720 $\mathrm{nm}$ - Fe oxides) and organic carbon $(1730,2160 \mathrm{~nm}$ and $2310 \mathrm{~nm})$. The results of this study show that vis-NIRS can provide very successful and direct determination of Dexter index on a field scale through its correlation to both OC and clay.

KEYWORDS: NIRS, soil quality, clay/organic carbon ratio

\section{INTRODUCTION}

The recently presented Dexter et al. (2008) ${ }^{1}$ threshold (ratio of clay to organic carbon (OC) of $10 \mathrm{~kg} / \mathrm{kg}^{-1}$ ) is a good indicator for numerous soil functional properties. For soils with a clay/OC $<10$, non-complexed OC is available for soil structure buildup and important biophysical functions. Soils with clay/OC $>10$ have critically high clay to $\mathrm{OC}$ ratio and reduced functionality which may cause reduced aggregate stability and potentially have a negative effect on yields of agricultural crops.

Conventional analysis of $\mathrm{OC}$ and clay are costly and time consuming, thus an alternative method to quantify $\mathrm{OC}$, clay or clay/OC ratio directly would be valuable. Visible near infrared spectroscopy (vis-NIRS) is a cost-effective analytical method which has been applied to soil analysis since the mid-1990's. The absorption in the vis region are associated with minerals containing iron (realted to clay due to metal-OH bend) and with organic matter (due to color) ${ }^{2}$. The NIR region is dominated by bonds characteristic of both organic and inorganic matter. Thus, there is a rational for using vis-NIRS to OC and clay estimation. Here, for the first time the feasibility of using vis-NIRS to predict clay/OC ratio by utilizing Partial Least Squares regression (PLSR) was tested.

\section{MATERIALS AND METHODS}

Soil samples originated from two agricultural fields (Silstrup and Sørvad) in north-western and western Denmark (Fig. 1). In Silstrup, 65 topsoil samples were collected on a $15 \mathrm{~m}$ grid. In order to select representative locations for soil sampling in Sørvad, a conditioned Latin Hypercube sampling (cLHs) strategy was applied. The use of CLHs in digital soil mapping was suggested by Minasny et al. (2006) ${ }^{3}$. 

This method ensures a full coverage of the range of each variable by maximally stratifying the marginal distribution. It can represent the complicated nature of a landscape variation well. cLHs sampling was based on the electrical conductivity (EC) data available for this field and terrain attributes ${ }^{4}$. In total 50 samples were collected at this site (Fig. 1).

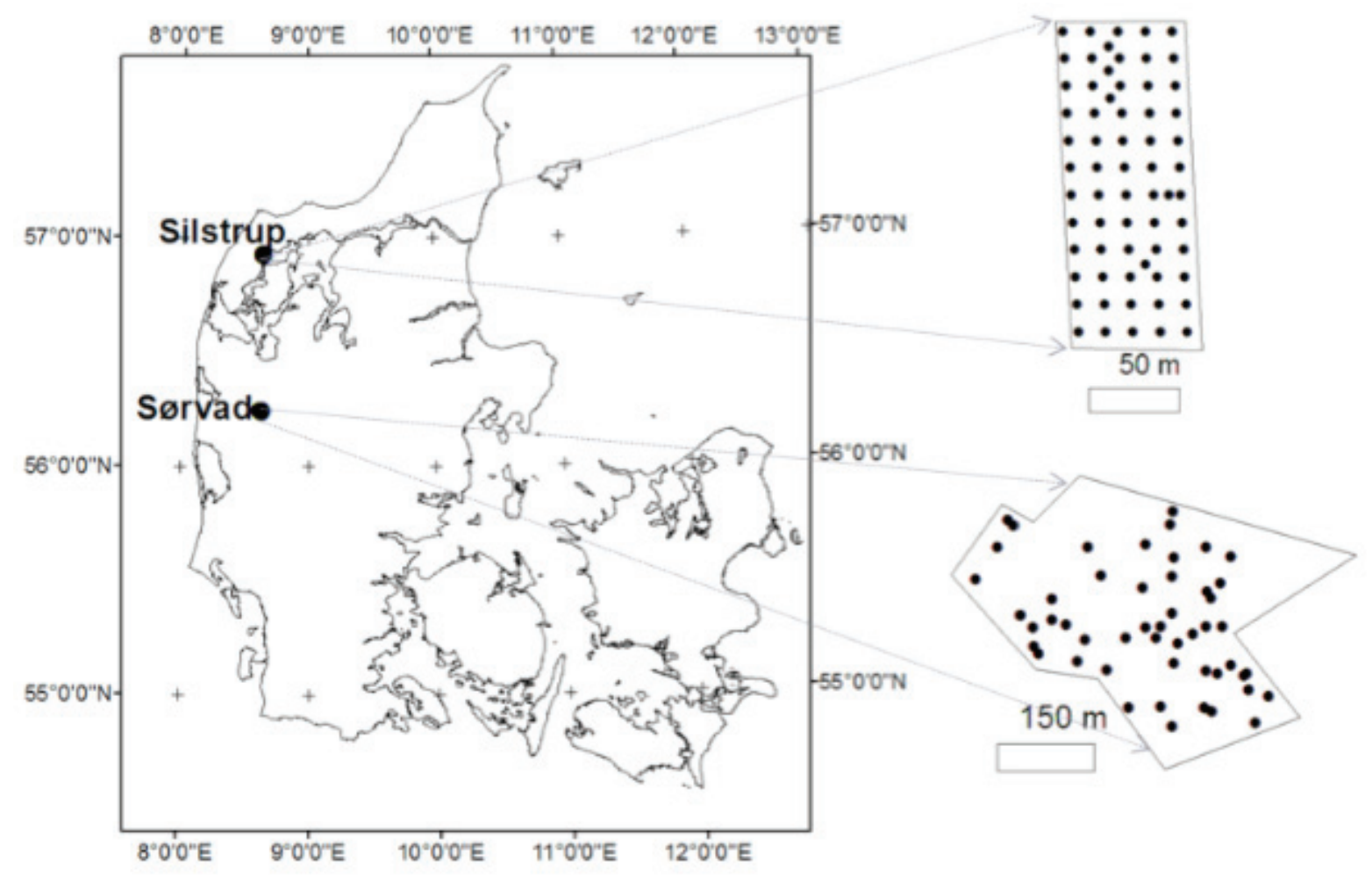

Figure 1. Location of the study sites.

Collected soil samples analyzed with the conventional laboratory methods for soil texture and organic carbon (OC). Soil texture was determined by a combination of wet-sieving and hydrometer methods. Soil organic carbon was determined on a FLASH 2000 organic elemental analyzer coupled to a thermal conductivity detector (Thermo Fisher Scientific, Walthman, MA, USA).

Spectral measurements were conducted on air dried and $2 \mathrm{~mm}$ sieved soils using vis-NIR (400-2500 nm) spectrometer DS2500 (Foss, HIllerød, Denmark). Approximately $40 \mathrm{~g}$ of soil were placed in a sample holder which rotated seven times during the analysis. At each position four spectra were collected and averaged into one representative spectrum per sample.

Partial Least Squares regression (full cross-validation) was performed on $80 \%$ randomly selected samples to correlate soil spectra with $\mathrm{OC}$, clay and clay/OC. The precision and robustness of calibration models was tested on the remaining $20 \%$ of the samples and evaluated using: root mean square error of prediction (RMSEP); ${ }^{2}$; and a ratio of performance to inter-quartile range (RPIQ). Analysis of regression coefficients was also performed.

\section{RESULTS AND DISCUSSION}

The soil from the two study sites vary from very sandy ( $90 \%$ sand) to clayey ( $24 \%$ clay) and from lower $(1.5 \%$ $\mathrm{OC}$ ) to high in OC content (>6\%), giving clay/OC ratio between 1.20 and 10.43 (Table 1 ). 
Table 1. General statistics for the calibration and the validation datasets

\begin{tabular}{ccccccc}
\hline & \multicolumn{2}{c}{ clay (\%) } & \multicolumn{2}{c}{ OC (\%) } & \multicolumn{2}{c}{ clay/OC } \\
\cline { 2 - 7 } & cal. (N=92) & val. (N=23) & cal. (N=92) & val. (N=23) & cal. (N=92) & val. (N=23) \\
\cline { 2 - 7 } Mean & 13.6 & 12.1 & 2.8 & 2.6 & 5.9 & 5.6 \\
Max & 24.9 & 18.5 & 6.3 & 7.5 & 10.2 & 10.4 \\
Min & 5.9 & 5.6 & 1.6 & 1.7 & 1.6 & 1.2 \\
SD & 3.9 & 4.4 & 1.4 & 1.4 & 2.8 & 2.9 \\
Skewness & -0.3 & -0.1 & 1.3 & 2.7 & -0.3 & 0.04 \\
Kurtosis & 0.2 & -1.5 & 0.1 & 7.4 & -1.5 & -1.4 \\
Median & 14.8 & 14.3 & 2.0 & 2.1 & 7.2 & 6.9 \\
Q1 & 10.6 & 8.5 & 1.9 & 1.9 & 2.8 & 3.3 \\
Q3 & 16.2 & 15.2 & 3.2 & 2.4 & 8.1 & 7.8 \\
\hline
\end{tabular}

Where: cal: calibration data set; val: validation data set; OC: organic carbon; SD: standard deviation;

Q1: the first inter- quartile; Q3: the third inter-quartile

Successful calibration and validation results for OC, clay and clay/OC ratio were generated (Table 2 and Fig. 2). The prediction of clay resulted in RMSEP $=0.9 \%, R 2=0.94$, and a high RPIQ (7). The highest values of the regression coefficient in the clay model were located at 541 and $640 \mathrm{~nm}$ (Fe oxides) and at 1412, 1910 and 2208 $\mathrm{nm}$ (OH bond) (Fig. 2).

Table 1. The results of Partial Least Squares regression for clay, OC and Dexter $\mathrm{n}$.

\begin{tabular}{ccccccc}
\hline & \multicolumn{2}{c}{ clay (\%) } & \multicolumn{2}{c}{ OC (\%) } & \multicolumn{2}{c}{ clay/OC } \\
\cline { 2 - 7 } & cal. (N=92) & val. (N=23) & cal. (N=92) & val. (N=23) & cal. (N=92) & val. (N=23) \\
\cline { 2 - 7 } RMSECV/ RMSEP & 1.2 & 0.9 & 0.3 & 0.2 & 0.5 & 0.4 \\
R2 & 0.91 & 0.94 & 0.94 & 0.96 & 0.97 & 0.97 \\
RPIQ & 6 & 7 & 4 & 5 & 11 & 11 \\
LVs & 6 & - & 8 & - & 6 & - \\
Q3 & 16.2 & 15.2 & 3.2 & 2.4 & 8.1 & 7.8 \\
\hline
\end{tabular}

Where: cal: calibration data set; val: validation data set; OC: organic carbon; RMSECV: room mean square error of calibration; RMSEP: root mean square of prediction; RPIQ: Q1-Q3/RMSEP; LV's: number of latent variables

The OC content was predicted with a RMSEP of $0.2 \%, \mathrm{R}^{2}$ of 0.96 and RPIQ of 5 . The important wavebands were related to soil organic matter $(780,1727,2311$ and $2330 \mathrm{~nm})$, Fe oxides $(442,490,560 \mathrm{~nm})$ and OH bonds (1908 and $2208 \mathrm{~nm}$ ) (Fig. 2). The most successful predictive ability reported was interestingly of the clay/OC ratio (RMSEP=0.4, $\mathrm{R}^{2}=0.97, \mathrm{RPIQ}=11$ ). The most important absorption bands were related to both clay minerals (1421, 1910 and $2206 \mathrm{~nm}-\mathrm{OH}$ bonds and 429, $720 \mathrm{~nm}$ - Fe oxides) and organic carbon (1730, $2160 \mathrm{~nm}$ and 2310 nm) (Fig. 2). 

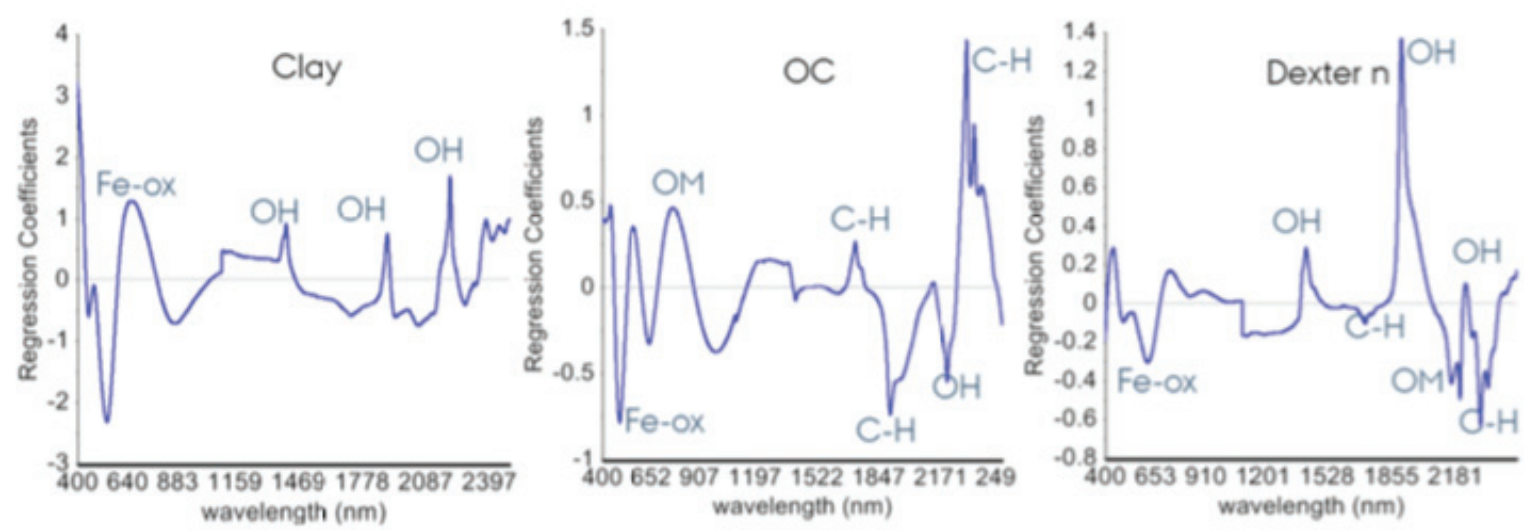

Figure 2. Regression coefficients from clay, OC and clay/OC ratio PLSR models.

\section{CONCLUSION}

The results of this study show that vis-NIRS can provide very successful and direct determination of clay/OC ratio on a field scale through its correlation to both $\mathrm{OC}$ and clay. Further studies across different soil types will be conducted.

\section{Acknowledgments}

Financial support for this work came from the soil-spec project funded by the GUDP program (Grønt Udviklingsog Demonstrationsprogram) from the Ministry of Food, Agriculture, and Fisheries of Denmark.

\section{References}

1. Dexter, A.R.; Richard, G.; Arrouays, D.; Czyz, E.A.; Jolivet C.; Duval, O. Complexed organic matter controls soil physical properties. Geoderma, 2008, 144, 620-627.

2. Stenberg, B.; Viscarra Rossel, R. A.; Mouazen, A. M; Wetterlind, J. Visible and near infrared spectroscopy in soil science. Advances in Agronomy, 2010, 107, 163-512.

3. Minasny, B.; McBratney A. B. A conditioned Latin hypercube method for sampling in the presence of ancillary information. Computers and Geosciences, 2006, 32, 1378-1388.

4. Knadel, M.; Peng, Y.; Schelde, K.; Thomsen, A.; Deng, F.; Greve, M. H. Optimal sampling and sample preparation for NIR-based prediction of field scale soil properties, EGU General Assembly 2013, Vienna, 7-11 April 2013. 